\title{
Long-Term Enzymatic and Phenotypic Correction in the Phenylketonuria Mouse Model by Adeno-Associated Virus Vector-Mediated Gene Transfer
}

\author{
HYUN-JEONG OH, EUN-SOOK PARK, SEONGMAN KANG, INHO JO, AND SUNG-CHUL JUNG \\ Department of Biomedical Sciences, National Institute of Health, Seoul 122-701, Korea [H.J.O, I.J., \\ S.C.J.], BK21 Project for Biomedical Science, Yonsei University, Seoul 120-752, Korea [E.S.P.], \\ Graduate School of Life Sciences and Biotechnology, Korea University, Seoul 136-701, Korea [H.J.O,
} S.K.]

\begin{abstract}
ABST
Phenylketonuria (PKU) is an autosomal recessive metabolic
disorder caused by a deficiency of phenylalanine hydroxylase
(PAH). The accumulation of phenylalanine leads to severe men-
tal and psychomotor retardation, and hypopigmentation of skin
and hair. Low-phenylalanine diet therapy can prevent irreversible
damage if instituted from birth. However, poor compliance with
the strict lifelong dietary therapy leads to various neurologic and
behavioral problems. To develop a safe and promising gene
therapy method for PKU, we investigated whether a recombinant
adeno-associated virus could be used as a PAH gene transfer
vector to reduce the excessive phenylalanine level in the PKU
mouse model. A recombinant adeno-associated virus vector en-
coding the human PAH gene (rAAV-hPAH), driven by EF1- $\alpha$
promoter, was infused into PAH-deficient mice, Pah $h^{\text {enu2 }}$, via the
hepatic portal vein. Two weeks after injection, the plasma phe-
nylalanine level dramatically decreased to $360 \mu \mathrm{M}$ in male PKU
mice, accompanied by the coat color changing to black. The
mean plasma phenylalanine level of untreated PKU mice was
$1800 \mu \mathrm{M}$. The PAH enzyme activities of treated mice increased
to $10-17 \%$ of wild-type mice. No signs of liver toxicity were
\end{abstract}
observed after gene transfer. The biochemical and phenotypic corrections were sustained for up to 25 wk (25-wk detection period). In contrast, the treatment was less effective in female PKU mice. These results indicate that recombinant adenoassociated virus vector-mediated gene therapy can be a useful therapeutic candidate for patients with PKU. Further studies are needed to clarify the differences in PKU pathogenesis in males and females, and to explore alternative administration routes besides hepatic portal vein injection. (Pediatr Res 56: 278-284, 2004)

PKU, phenylketonuria

\section{Abbreviations}

PAH, phenylalanine hydroxylase

AAV, adeno-associated virus

rAAV-hPAH, recombinant adeno-associated virus vector encoding human phenylalanine hydroxylase cDNA

$\mathbf{B H}_{4}$, tetrahydrobiopterin

RT-PCR, reverse-transcriptase polymerase chain reaction TLC, thin layer chromatography
PKU (MIM 261600) is an autosomal recessive metabolic disorder caused by a number of mutations, primarily singlebase substitutions, in the PAH gene, located on chromosome 12q22-24.1 $(1,2)$. This disorder is characterized by the disruption of phenylalanine metabolism due to the lack of phenylalanine hydroxylase activity. PAH (L-phenylalanine-4monooxygenase, EC 1.14.16.1), predominantly expressed in

Received September 8, 2003; accepted March 29, 2004.

Correspondence: Sung-Chul Jung, M.D., Ph.D., Division of Genetic Disease, Department of Biomedical Science, National Institute of Health, 5 Nokbun-Dong, Eunpyung-Gu, Seoul 122-701, Korea; e-mail: scjung@nih.go.kr

Supported by a grant of the Korea 21 R\&D Project, Ministry of Health and Welfare, Republic of Korea (01-PJ10-PG6-01GN15-0001).

DOI: 10.1203/01.PDR.0000132837.29067.0E liver, catalyzes the conversion of the essential amino acid phenylalanine into tyrosine using $\mathrm{BH}_{4}$ as a cofactor $(3,4)$. The loss of this enzymatic activity results in the accumulation of phenylalanine and its abnormal derivatives in the blood and other tissues. Excessive blood phenylalanine concentration causes severe mental and psychomotor retardation from toxicity to the CNS, although the exact mechanism is not well known, and other clinical symptoms such as hypopigmentation of skin, hair, and eyes, growth failure, and "mousy" odor $(5,6)$.

These symptoms can be prevented by a strict, lifelong dietary restriction of phenylalanine from early infancy. Although relatively successful, dietary therapy is a heavy burden on patients and their families and leads to poor compliance, particularly in adolescents and young adults $(7,8)$. Poor com- 
pliance or discontinuation of dietary therapy can result in various neurologic and behavioral problems, such as loss of intellectual function, tremor, and hyperactivity (9). In addition, increased blood phenylalanine through noncompliance to diet during pregnancy has an effect on offspring, leading to birth defects (10).

Many studies have been performed to develop methods that can efficiently remove excessive phenylalanine from body fluids, to replace the arduous dietary treatment. Generally, gene transfer technology has been used to deliver recombinant PAH gene into somatic cells and restore functional protein (11-14). The gene transfer experiments using recombinant retrovirus and DNA-protein complexes provided profound effectiveness in vitro, but there has been little progress in vivo because of low transduction efficiencies and limitations of application (12, 13). Although a recombinant adenovirus-mediated gene delivery method displayed sufficient therapeutic effect to normalize serum phenylalanine levels soon after intraportal infusion, prolonged correction was not detected owing to the immune response against the adenoviral vector $(12,14)$. Repeated administration of immunosuppressants was required to block the host immune reaction and elicit persistent reversal of hypopigmentation, a characteristic of PKU (14).

In this study, we used the recombinant $\mathrm{AAV}$ vector as a gene delivery vehicle. AAV is a small, nonenveloped, singlestranded DNA virus that is not pathogenic in humans and could transduce a variety of cell types, both dividing and terminally differentiated cells, inducing sustained therapeutic gene expression and relatively weak immune response $(15,16)$. It has been widely used for gene therapy studies in inherited diseases such as hemophilia B $(17,18)$ and Fabry disease $(19)$ with promising results. Here, we report the cognitive outcome of biochemical and phenotypic reversal by the AAV-mediated gene delivery of a human PAH transgene.

\section{MATERIALS AND METHODS}

Production of rAAV-hPAH viral vector. The parent plasmid pAAV-EF-eGFP-WPRE-BGHpoly(A), based on AAV type 2, was created as previously described (20) with minor modification. Full-length human PAH cDNA, phPAH247 (American Type Culture Collection, Manassas, VA, U.S.A.) was subcloned into pAAV-EF-eGFP-WPRE-BGHpoly(A) by substitution with eGFP cDNA. The rep/cap plasmid, pAd/AAV, and the adenovirus helper plasmid, pAd12, were used to produce rAAV-hPAH. All three plasmids, pAAV-EF-hPAH-WPREBGHpoly(A), pAd/AAV, and pAd12, were transfected into 293 cells using calcium phosphate. At $48 \mathrm{~h}$ after transfection, cells were pelleted by centrifugation and resuspended in $5 \mathrm{~mL}$ of tissue dissociation buffer $(140 \mathrm{mM} \mathrm{NaCl}, 5 \mathrm{mM} \mathrm{KCl}, 0.75$ $\mathrm{mM} \mathrm{K}_{2} \mathrm{HPO}_{4}, 25 \mathrm{mM}$ Tris-HCl, $\mathrm{pH}$ 7.4). The cell pellet was thawed at $37^{\circ} \mathrm{C}$, and Benzonase (Sigma Chemical, St. Louis, MO, U.S.A.) was added to a final concentration of $20 \mathrm{U} / \mathrm{mL}$. Sodium deoxycholate (Sigma Chemical) was added to a final concentration of $0.5 \%$ and the suspension was incubated for $1 \mathrm{~h}$. The homogenate was purified and concentrated by cesium chloride (Sigma Chemical) density gradient ultracentrifugation. Fractions with a refractory index of $1.371-1.373$ were pooled and dialyzed (Pierce Chemical, Rockford, IL, U.S.A.) against PBS. Refractory indices were determined using a refractometer (Leica, Buffalo, NY, U.S.A.). The rAAV-hPAH genomic titer was determined by real-time quantitative PCR using the ABI7700 (Applied Biosystems, Foster City, CA, U.S.A.), in which the signal from aliquots of test material is compared with a standard signal generated using the linearized pAAV-EF-hPAH-WPRE-BGHpoly(A) plasmid.

Cell lines. Human embryonal kidney cell line, 293T, hepatoma cell line, HepG2, and NIH3T3 cell line were propagated in Dulbecco modified Eagle medium supplemented with heatinactivated $10 \%$ fetal bovine serum and antibiotics.

Animals. The animal protocol was approved by the Korean National Institutes of Health intramural research committee. All animals were treated according to the Korea Food and Drug Administration and National Institutes of Health guidelines for animal care. A pair of PAH-deficient mice, $P a h^{\text {enu } 2}$, purchased from the Jackson Laboratories (Bar Harbor, ME, U.S.A.), were maintained and bred to obtain sufficient numbers of Pah ${ }^{\text {enu2 }}$ homozygote mice for this study. Clinical features of the mouse model mirror those of patients with PKU, including pronounced hypopigmentation of the coat color as a result of reduced melanin biosynthesis, elevated serum phenylalanine level $(\geq 1800 \mu \mathrm{M})$, behavioral abnormalities, and maternal PKU syndrome $(21,22)$. Mice had unlimited access to water and a diet containing $18.0 \%$ protein without phenylalanine restriction (Rat \& Mouse 18\%, PMI Nutrition International, Brentwood, MO, U.S.A.) throughout the whole experimental period. Five- to six-week-old mice were anesthetized with ketamine/xylazine and injected with $2 \times 10^{11}$ or $2 \times 10^{12}$ viral particles of rAAV-hPAH into the hepatic portal vein, tail vein, and the right quadriceps muscle. Animals were killed and analyzed at 2, 5, 15, and $25 \mathrm{wk}$ after rAAV-hPAH administration. At least three $P a h^{\text {enu } 2}$ homozygote mice were grouped and treated for experiment at each time point. Blood samples were collected at various time points. The liver, kidney, heart, and lungs were isolated from each $\mathrm{rAAV}$-injected $P a h^{\text {enu2 }}$ mouse along with age-matched wild-type control mice and untreated $P a h^{\text {enu } 2}$ mice for analysis.

Plasma phenylalanine assay. Quantitative analysis of plasma phenylalanine and tyrosine was carried out using HPLC (Biochrom20, Pharmacia, Cambridge, UK). The method involves deproteinization of a small sample volume of plasma $(300 \mu \mathrm{L})$ followed by HPLC on a cation-exchange resin column, PEEK (lithium form, $9 \mu \mathrm{m}, 46 \times 250 \mathrm{~mm}$ ). Ninhydrin reacts with the amino acids to form colored compounds, and these reactants are quantified by UV detection at $570 \mathrm{~nm}$. The flow rate was $25 \mathrm{~mL} / \mathrm{h}$ in a gradient of six mobile phases $(\mathrm{pH}$ 2.80, pH 3.00, pH 3.15, pH 3.50, pH 3.55, LiOH), and the duration of each analysis was $170 \mathrm{~min}$. The detection limit for this method is $400 \mathrm{nM}$.

PAH enzyme assay. PAH enzyme assay in tissue was performed based on previously reported methods (23). Briefly, the frozen tissue was homogenized in $0.1 \mathrm{M} \mathrm{KH}_{2} \mathrm{PO}_{4}$ buffer $(\mathrm{pH}$ 7.0) containing $3 \mathrm{mM}$ DTT, and sonicated. The homogenate was centrifuged at $13,000 \times g$ for $20 \mathrm{~min}$ at $4^{\circ} \mathrm{C}$, and the supernatant was used for the PAH enzyme assay. The enzyme activity was assayed by measuring the production of $\left[{ }^{14} \mathrm{C}\right]$ ty- 
rosine from $\left[{ }^{14} \mathrm{C}\right]$ phenylalanine. The PAH enzyme assay was performed in $100 \mu \mathrm{L}$ containing $0.15 \mathrm{M} \mathrm{KCl}, 0.2 \mathrm{M} \mathrm{KH}_{2} \mathrm{PO}_{4}$ buffer (pH 6.8), $6 \mathrm{U}$ catalase, $0.1 \mu \mathrm{Ci}\left[{ }^{14} \mathrm{C}\right]$ phenylalanine (Amersham Pharmacia Biotech UK, Ltd., Buckinghamshire, UK), $0.1 \mathrm{mM}$ phenylalanine, $30 \mu \mathrm{L}$ of crude extract, and 10 $\mu \mathrm{L}$ of $\mathrm{BH}_{4}$ (Schircks Laboratories, Jona, Switzerland) solution containing DTT (final concentrations $1.8 \mathrm{mM}$ and $20 \mathrm{mM}$, respectively). The reaction was started by adding the $\mathrm{BH}_{4}$ DTT mixture. The reaction mixture was incubated at $37^{\circ} \mathrm{C}$ for $60 \mathrm{~min}$, stopped by boiling for $5 \mathrm{~min}$, and chilled for $5 \mathrm{~min}$. Then, $10 \mu \mathrm{L}$ of excess unlabeled phenylalanine and tyrosine $(1: 1, \mathrm{vol} / \mathrm{vol})$ was added to each tube to serve as carrier. Proteins were precipitated by centrifugation at $12,000 \times g$ for $10 \mathrm{~min}$. The $50 \mu \mathrm{L}$ of supernatant was then concentrated to 10 $\mu \mathrm{L}$ and applied on a TLC system (TLC Silica Gel 60 plates, Merck, Darmstadt, Germany) and developed in butanol:acetic acid:distilled water $(60: 15: 25$, v:v:v) at room temperature. Quantification for radioactivity of $\left[{ }^{14} \mathrm{C}\right]$ phenylalanine and converted $\left[{ }^{14} \mathrm{C}\right]$ tyrosine was done using the ImageQuant, after visualization with a PhosphoImager (Molecular Dynamics, Sunnyvale, CA, U.S.A.).

Western blot analysis. Protein extracts were isolated from transduced NIH3T3 cells and HepG2 cells. Thirty micrograms of protein was electrophoresed on a $10 \%$ polyacrylamide gel and blotted onto nitrocellulose membrane (Invitrogen, Carlsbad, CA, U.S.A.). The membrane was hybridized with a 1:200 dilution of mouse antibody against human PAH (Chemicon International, Temecula, CA, U.S.A.), and subsequently with a horseradish peroxidase-conjugated anti-mouse antibody (Santa Cruz Biotechnology, Santa Cruz, CA, U.S.A.). The signals were then visualized using ECL-Plus enhanced chemiluminescence (Santa Cruz Biotechnology).

Genomic DNA PCR analysis. Genomic PCR was performed using $100 \mathrm{ng}$ of total genomic DNA extracted from PKU mouse liver. Detection of the specific human PAH sequence was described in "RT-PCR analysis" above. Endogenous mouse $\beta$-actin genomic sequence was also amplified to equalize quantity (forward primer, 5'-TGACGGGGTCACCCACACTGTGC-CCATCTA-3'; reverse primer, 5'-CTAGAAG CATTTGCGGTGGACGATGGAGGG-3').

RT-PCR analysis. To assay distribution of recombinant viral vector in liver and other organs, RT-PCR was performed. Total RNA was isolated using an RNeasy Mini kit (QIAGEN $\mathrm{GmbH}$, Hilden, Germany). RT reaction was conducted using $100 \mathrm{pmol} / \mu \mathrm{L}$ random primer (Takara Shuzo, Kyoto, Japan). The PCR amplification reaction of the cDNA was performed on each RT reaction sample, negative controls, and "notemplate" controls using GeneAmp PCR System 9700 (Applied Biosystems). For detection of specific human phenylalanine hydroxylase sequence, the following primers were used at 25 pmol: forward primer, 5'-GAAAACCCAGGCTTGGGCAGG-3'; reverse primer, 5'-CCGAGAGGAAAGCAGGCCAGCCAC-3'. These primers amplify a 730-bp vectorspecific band. Primers to mouse $\beta$-actin were used as an internal control (530 bp) (forward primer, 5'-CCCACACTGTGCCCATCTAC-3'; reverse primer, 5'-AGTACTTGCGCTCAGGAGGA-3'). After PCR amplification, samples were electrophoresed on $1 \%$ agarose gels and visualized with ethidium bromide. Gels were photographed with UV illumination and scored as positive only if a product band was easily visible.

Anti-IgG immune response. Sera were collected at 1, 2, and $5 \mathrm{wk}$ after injection, and the antibody response against total IgG was measured by ELISA (Roche Molecular Biochemicals, Mannheim, Germany). Briefly, 96-well, flat-bottom microtiter plates were coated with anti-mouse-Fc and blocked. Subsequently, sera were serially diluted in blocking reagent and incubated. After washing, the conjugate mixture (anti-mouse$\kappa$-POD and anti-mouse- $\lambda$-POD) was added and incubated. ABST substrate was added and incubated. The OD at $405 \mathrm{~nm}$ was determined with a Versamax Microplate reader (Molecular Devices, Menlo Park, CA, U.S.A.).

Statistical analysis. The statistical significance levels of differences between groups were determined using $t$ test. The data are presented as mean $\pm \mathrm{SD}$.

\section{RESULTS}

Expression and activity assay of rAAV-hPAH after in vitro transduction. Because PAH activity is not present in NIH3T3 cells, we used these cells as the negative control cell line for the in vitro assay. The transgene, human PAH cDNA, was driven by a human elongation factor $1-\alpha$ promoter and endowed with more stability by woodchuck hepatitis virus posttranscriptional regulatory element (WPRE), and the polyadenylation site was provided by the BGH poly(A). NIH3T3 cells were infected at an MOI of 1000 , at $60 \%$ cell density. Two days after injection, protein was isolated from rAAV-hPAH transduced, untransduced, and rAAV-eGFP mock-transduced cells and used for detection of enzyme expression and activity (Fig. 1). NIH3T3 cells infected with rAAV-eGFP and hepa-

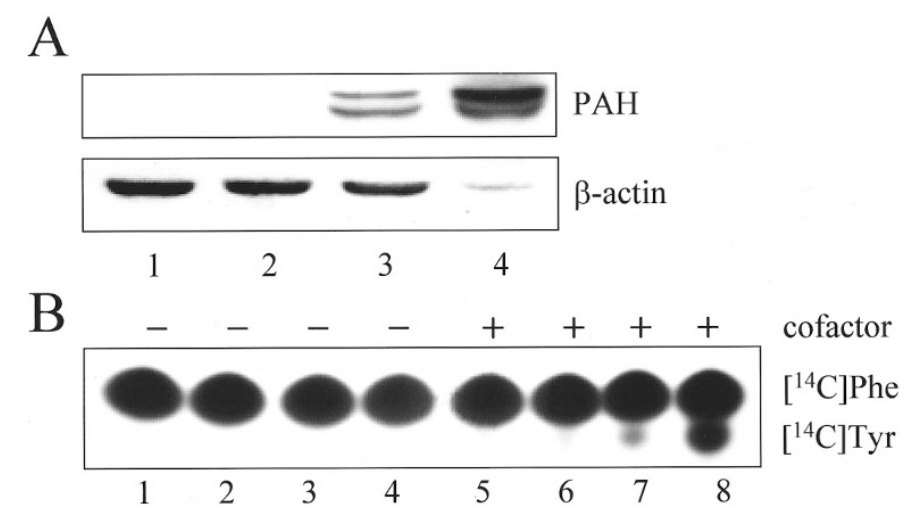

Figure 1. Western blot analysis and enzyme activity assay in NIH 3T3 cells infected with rAAV-hPAH. Analysis was performed at $2 \mathrm{~d}$ posttransduction with rAAV-hPAH at MOI of 1000. (A) 52-kD bands were detected on immunoblots of cells transduced with rAAV-hPAH (lane 3) and not found in untransduced (lane 1) or rAAV-eGFP mock-transduced cells (lane 2). The positive control band in HepG2 cells was sited at $52 \mathrm{kD}$ (lane 4). The presenting two bands may represent two different glycosylation states or the phosphorylation/nonphosphorylation forms of PAH. (B) PAH enzyme activity detection by TLC. Phenylalanine has a higher $\mathrm{R}_{\mathrm{F}}$ than tyrosine in this system. Assays were conducted in the presence (lanes 5-8) and the absence (lanes 1-4) of $\mathrm{BH}_{4}$ cofactor. Lanes 1 and 5, untransduced cells; lanes 2 and 6 , rAAV-eGFP mock-transduced cells; lanes 3 and 7, cells transduced with rAAV-hPAH; lanes 4 and 8 , positive control, human hepatoma cell line HepG2. 
toma cell line HepG2 were used as negative and positive controls, respectively. The rAAV-hPAH transduction resulted in human PAH expression in the transduced cells, but there was no expression in the untransduced or rAAV-eGFP mockinfected control (Fig. 1A). Protein bands (52 kD) were observed in HepG2 positive control cells and transduced cells, using a monospecific anti-PAH antibody. The enzyme activity assay measuring the conversion of $\left[{ }^{14} \mathrm{C}\right]$ phenylalanine to $\left[{ }^{14} \mathrm{C}\right]$ tyrosine also showed results consistent with the Western blot analysis (Fig. 1B).

In vivo expression of PAH after delivery of virus. Basal plasma phenylalanine level of untreated PKU mal mice was $1800.6 \pm 233.7 \mu \mathrm{M}$. Plasma phenylalanine levels in male mice infused with high titer viral vectors $\left(2 \times 10^{12}\right.$ viral particles $)$ dramatically decreased to $360 \pm 160 \mu \mathrm{M}$ at $2 \mathrm{wk}$ (outset point of detection), and showed continued statistically significant levels of decrease, $253.3 \pm 104.9,352.3 \pm 28.11$, and $667.0 \pm$ $91.0 \mu \mathrm{M}$ at 5, 15, and $25 \mathrm{wk}$ after injection, respectively (Fig. 2).

Plasma phenylalanine levels in treated female mice infused with $2 \times 10^{12}$ viral particles were $1183 \pm 667 \mu \mathrm{M}$ at $5 \mathrm{wk}$ after injection, although the plasma phenylalanine levels in untreated female mice were higher than in untreated male mice, $2887 \pm 648.7 \mu \mathrm{M}$. Treatment with low-dose viral particles $\left(1 \times 10^{11}\right)$ was not effective for reducing plasma phenylalanine level in either male or female mice.

Coat color change in treated male PKU mice gradually progressed from a grayish to black color. At $2 \mathrm{wk}$ after delivery of rAAV-hPAH, the groups contained some fully black-coated mice and some partially black mice (Fig. 3). Sustained coat color changes were detected over the whole experimental period. Slight coat color changes in treated female mice were observed from $2 \mathrm{wk}$ after injection, but female PKU mice were easily distinguished from wild-type mice.

Significant enzymatic activities were observed at 2, 5, 15 and 25 wk in PKU male mice treated with the high titer (Fig. 4). Hepatic PAH activities recovered, in high titer viral vectorinjected PKU mice, to levels ranging from $9.5 \%$ to $17 \%$ of

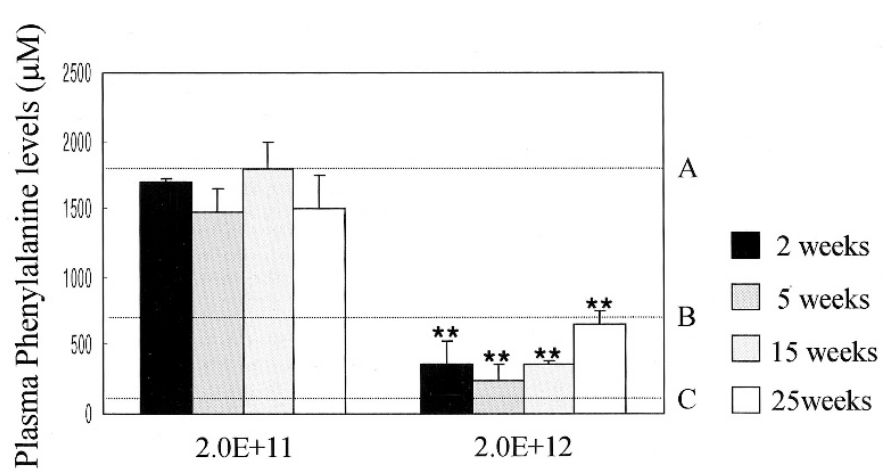

Figure 2. Plasma phenylalanine concentrations in $\mathrm{Pah}^{\text {enu } 2}$ mice after rAAV$\mathrm{hPAH}$ treatment. The dotted line $A$ shows plasma phenylalanine concentration of untreated $P a h^{\text {enu2 }}$ mice; dotted line $B$, recommended maximum value by the National Society for PKU (UK); dotted line $C$, plasma level in normal control animals. Values are presented as the mean \pm SD. Plasma phenylalanine levels in treated mice were compared for statistically significant differences from those in untreated mice. ${ }^{* *} p<0.001$ vs untreated Pah $^{\text {enuz } 2}$ mice $(n=3$ for respective experimental time point, $n=5$ for untreated $\mathrm{Pah}^{\text {enu2 }}$ mice). wild-type mice. The low titer viral vector-administered male mice recovered only $6 \%$ of the normal PAH activity by $5 \mathrm{wk}$ after injection. There was consistency between the hepatic enzyme activity and the reduction of plasma phenylalanine concentration at each time point (data not shown). Semiquantitative PCR using genomic DNA isolated from liver showed a decrease in recombinant DNA copy numbers at $25 \mathrm{wk}$ after injection (Fig. 5A). The hepatic PAH activity in PKU female mice treated with rAAV-hPAH was under the detection level in TLC analysis, although the same amounts of recombinant DNA copies were found in female mice as those in male mice at $5 \mathrm{wk}$ (Fig. 5A). Liver, spleen, kidney, heart, and lung from male mice, collected at $15 \mathrm{wk}$ after injection, were examined using RT-PCR. Human PAH recombinant DNA was detected only in liver, not in the other organs examined (Fig. 5B).

Comparison of therapeutic efficiencies by various administration routes. To compare whether therapeutic effect varies by changing administration routes, hepatic portal vein, tail vein, and intramuscular routes were investigated (Fig. 6). Only hepatic portal vein injection, but not tail vein injection and intramuscular injection, resulted in a significant decrease of plasma phenylalanine concentration to within the desired therapeutic range, reflecting the availability of transferred hPAH metabolic function in liver.

Examination of potential immune response and liver toxicity. Sera were collected at 1,2 , and $5 \mathrm{wk}$ after injection and analyzed for anti-IgG antibody by ELISA. There was no significant difference in IgG levels in all sera from control and transduced mice at all time points. Various hepatic enzymes were tested to determine whether any liver damage and toxicity occurred due to the liver direct delivery of rAAV-PAH through the hepatic portal vein. At d 3, levels of untreated and rAAV$\mathrm{hPAH}$-treated mice were $40 \pm 7.8 \mathrm{U} / \mathrm{L}$ and $22.3 \pm 4.8 \mathrm{U} / \mathrm{L}$ for alanine transaminase and $221 \pm 87 \mathrm{U} / \mathrm{L}$ and $105.33 \pm 55.4$ for aspartate transaminase, respectively. There were no differences of these values at $d 7$. The levels of total bilirubin in the untreated and treated groups were both $0.1 \mathrm{mg} / \mathrm{dL}$, which was within the normal range.

\section{DISCUSSION}

Gene therapy for patients with PKU would be one of useful therapeutic candidates to prevent brain damage due to discontinuation of the arduous dietary restriction treatment. The adenovirus vector-mediated PAH gene transfer has been reported with successful coat color change in PKU mice (14). In this previous study, adenovirus-mediated gene transfer normalized the serum phenylalanine level within $24 \mathrm{~h}$ and changed coat color to black. Because the biochemical and phenotypic changes are important criteria for evaluating amelioration of PKU symptoms, this was an encouraging outcome in assessing the feasibility of gene therapy for PKU. However, administration of the immunosuppressant FK506 was required to block the host immune response to the adenovirus vector and to induce prolonged therapeutic effect. When the safety and the application to neonates in the clinic were considered, the practical use of adenovirus-mediated PAH gene transfer was considered inappropriate. The immunogenicity could reduce 

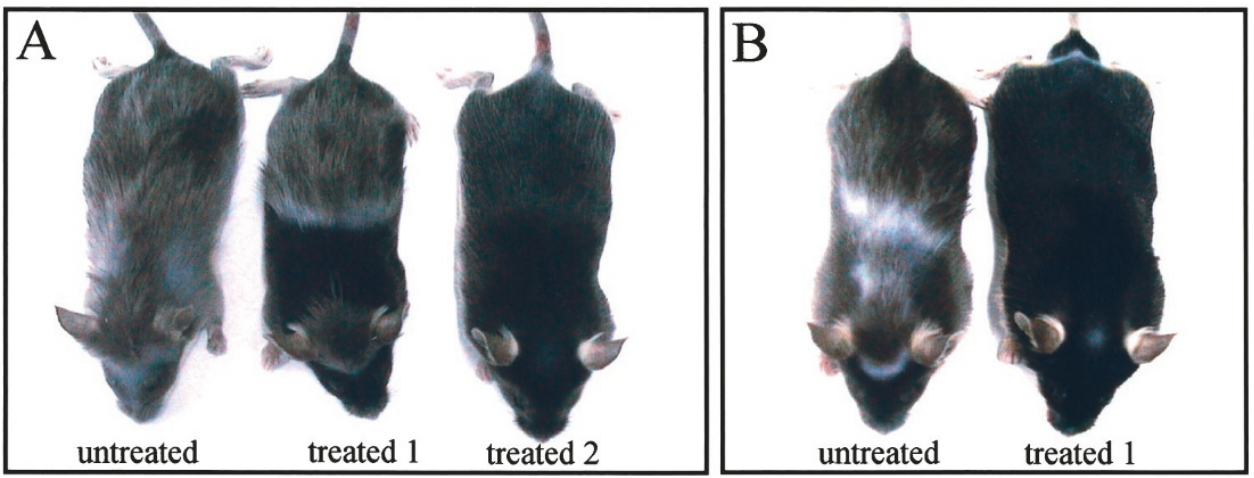

Figure 3. Coat color reversal to black in rAAV-hPAH treated $P a h^{\text {enu } 2}$ mice. $(A)$ Mice administered with $2 \times 10^{12}$ viral particles displayed pigmentation at 2 wk after injection, the groups contained some fully black-coated mice and some partially black mice. (B) Coat color change at 5 wk after injection. Sustained coat color changes were detected over the whole experimental period.
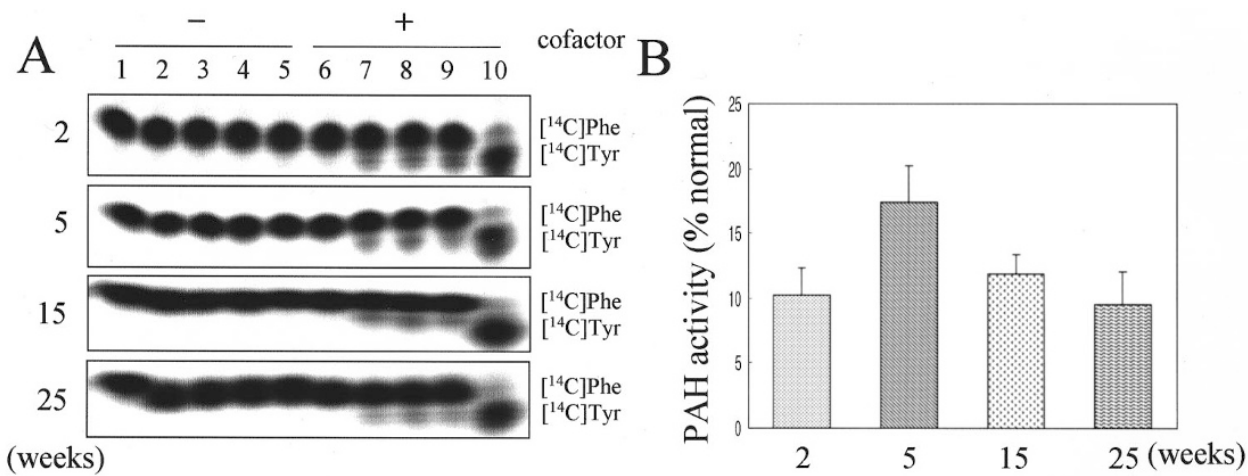

Figure 4. Levels of PAH enzyme activities of $P a h^{e n u 2}$ mice after rAAV-hPAH treatment. $(A)$ A thin layer chromatogram of phenylalanine hydroxylase assay. Assays were conducted in the presence (lanes 6-10) and the absence (lanes 1-5) of $\mathrm{BH}_{4}$ cofactor. Lanes 1 and 6, untreated PKU mice; lanes 2-4 and 7-9, treated mice; lanes 5 and 10, wild-type mice. $(B)$ The levels of enzymatic activities represented as a percentage of that found in wild-type mice. Each spot from reaction by transferred phenylalanine hydroxylase was analyzed by densitometric scanning, and intensities were quantitated. Values are presented as the mean \pm SD.

efficacy of the transferred gene and hamper successful application. The AAV-mediated gene delivery method used in our study has minimal antigenicity and enables the induction of the desired outcome without obstruction by neutralizing antibodies. In fact, our data demonstrated a minimal development of neutralizing antibody in response to transferred recombinant viral vector containing $\mathrm{PAH}$, as previously reported with AAV-mediated gene therapy $(19,24)$. Furthermore, we sought to determine whether a specific liver toxicity appeared after injections of the viral vector through the hepatic portal vein, and also found no differences in plasma aspartate transaminase, alanine transaminase, and total bilirubin, markers for hepatic damage.

Our data demonstrate that the biochemical and phenotypic change sustained without immunosuppressants were long term. The decrease in plasma phenylalanine level was most obvious in the group infused directly to the liver through the hepatic portal vein with $2 \times 10^{12}$ viral particles. The lowest plasma phenylalanine concentration was detected $5 \mathrm{wk}$ after injection, and elevation of this value was observed at $25 \mathrm{wk}$. Although the plasma phenylalanine level in mouse is unlikely to be translated to humans, the levels achieved were within the values recommended by the National Society for PKU (UK) (below $480 \mu \mathrm{M}$ in the $1-10 \mathrm{y}$ age group, and below $700 \mu \mathrm{M}$ in people older than $10 \mathrm{y})(8)$. The semiquantitative genomic PCR analysis showed that the increase in plasma phenylalanine
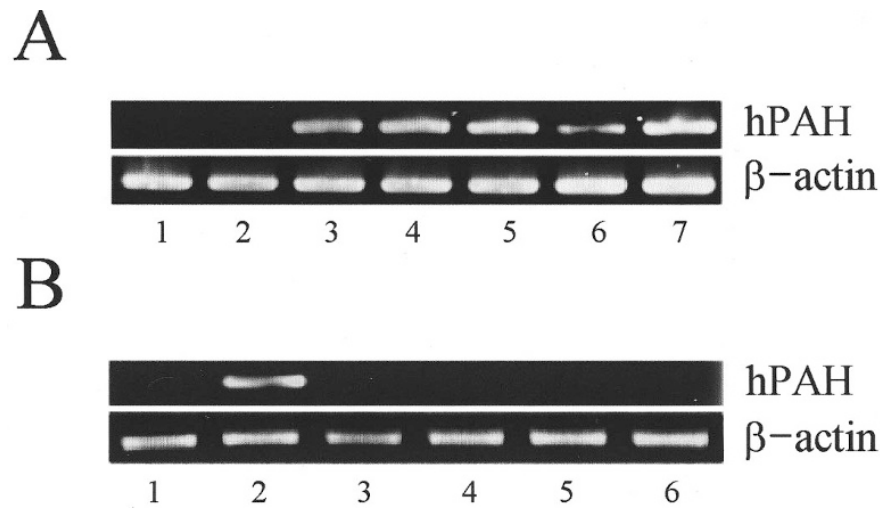

Figure 5. Tissue distribution and estimation of vector genome in liver of after hepatic portal vein administration. (A) Semiquantitative PCR was performed to analyze rAAV vector genomes in the rAAV-transduced liver at various time points. Genomic DNA (100 ng) from untreated and treated liver was PCR amplified. The vector-specific fragment from genomic DNA of transduced liver is $730 \mathrm{bp}$ in length. Internal control, genomic $\beta$-actin amplification was performed for equal quantification. Lane 1, untreated $P a h^{\text {enu2 }}$ mouse; lane 2, untreated wild-type mouse; lanes $3-6$, treated $P_{a h}^{\text {enu } 2}$ male mice at time points $2,5,15$, and $25 \mathrm{wk}$, respectively; lane 7 , treated $P_{a h^{\text {enu } 2}}$ female mouse at 5 wk after treatment. (B) Sampling was performed at $15 \mathrm{wk}$ after treatment $\left(2 \times 10^{12}\right)$. Transgene expressions were determined using specific human PAH primer in various tissues. Lane 1, untreated PKU mouse liver; lane 2, treated PKU mouse liver; lane 3, treated PKU mouse spleen; lane 4, treated PKU mouse kidney; lane 5, treated PKU mouse lung; lane 6, treated PKU mouse heart. 


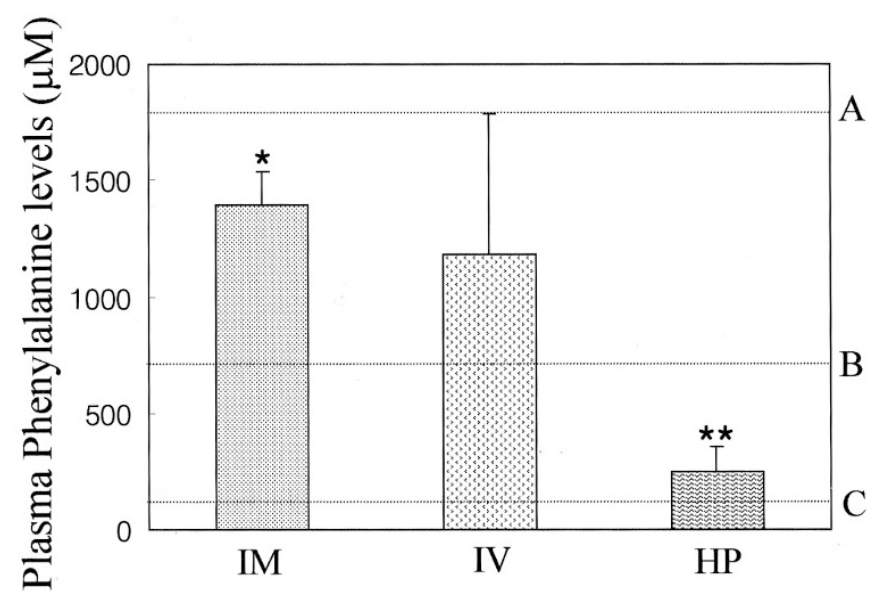

Figure 6. Plasma phenylalanine concentrations of $P a h^{\text {enu2 }}$ mice after rAAVhPAH treatment through various administration routes. Pah ${ }^{\text {enu } 2}$ mice were administered with $2 \times 10^{12}$ viral particles and killed at $5 \mathrm{wk}$ after injection. The dotted line $A$ shows plasma phenylalanine concentration of untreated $\mathrm{Pah}^{\text {enu } 2}$; dotted line $B$, recommended maximum value by the National Society for PKU (UK); dotted line $C$, plasma level in normal control animals. Values are presented as the mean $\pm \mathrm{SD} .{ }^{*} p<0.05,{ }^{* *} p<0.001$ vs untreated Pah ${ }^{\text {enu }}$ mice ( $n=3$ for respective time point, $n=5$ for untreated $P_{a h^{\text {enu }}}$ mice).

level was due to the loss of the extrachromosomal vector genome. Nevertheless, the range remained below the level $(<900 \mu \mathrm{M})$ recommended to prevent brain damage (25). When AAV vector stably transduced hepatocytes in experimental animals, nonintegrated extrachromosomal genomes were reported to be the major form of recombinant AAV in the liver and to be the primary source of recombinant AAV-based gene expression $(26,27)$. It raised uncertainty whether rAAVhPAH expression could offer efficient lifelong treatment after single-dose administration. More stable and distinct outcomes might be achieved by changing regulatory elements and clarifying genotoxic causes that affect the stability of extrachromosomal genome, in addition to boosting of viral particles.

The PAH enzyme activities in the liver were closely correlated with plasma phenylalanine level and coat color change. This was a logical consequence, as tyrosine is synthesized from phenylalanine by $\mathrm{PAH}$ and is a precursor of melanin, which is important for coat color. In our experiments, the liver PAH enzyme produced activity that peaked at $17.4 \pm 2.9 \%$ at $5 \mathrm{wk}$ after injection, and declined progressively to $9.5 \pm 2.6 \%$ at 25 wk, consistent with the plasma phenylalanine level. Reversal of hypopigmentation was detected from $10 \mathrm{~d}$ after administration and lasted for the whole experimental duration. At $25 \mathrm{wk}$, it is still difficult to distinguish the treated from wild-type normal mouse by coat color. All these results suggest that about $10-20 \%$ of the normal enzymatic activity is enough to restore the phenylalanine levels regarded as safe.

Subsequently, we conducted gene therapy on female $\mathrm{Pah}^{\text {enu } 2}$ mice and observed no normalization in coat color or plasma phenylalanine level. Although transduction efficiency of infused rAAV-hPAH in liver of $\mathrm{Pah}^{\text {enu2 }}$ female mouse was same as that of male mouse, the hepatic PAH activities in treated $P_{a h}{ }^{\text {enu } 2}$ female mice were almost silent. Laipis et al. (28) previously reported that ovariectomy and implantation of a time-release testosterone pellet were required for treatment of female PKU mice differently from PKU male mice. Pah ${ }^{\text {enu }}$ female mice differ from the males in endocrine activity and often have higher plasma phenylalanine levels than males. This would probably contribute to resistance in the females to AAV-mediated gene therapy. Further experiments remain to be performed, including characterization of the pathogenesis in females, identifying different susceptibilities by sex hormone, and identifying a more potent promoter for females to enhance us to apply gene therapy for female patients with PKU.

The hepatic portal vein is conventionally used as a way to transfer the therapeutic gene to compensate for a defective gene that is normally expressed in the liver. However, there are limitations in clinical application in delivering recombinant viral vectors into the hepatic circulation via intraportal injection, as surgery is involved. Treatment of most metabolic diseases, such as PKU, needs to be initiated early in the neonatal period to protect from brain damage. Therefore, it is necessary to investigate less invasive, more efficient, and simple delivery routes for prospective application to neonate patients. A study with such an objective reported that the clearance of phenylalanine by expression of phenylalanine hydroxylase and GTP-cyclohydrolase through genetic engineering in primary human skin keratinocytes was obtained (29). If a few limitations such as clearance yields were modified, this strategy would be a useful approach to the treatment of PKU. Among administration routes tested in our studies, liver-directed gene delivery through the hepatic portal vein was most effective. Intramuscular and intravenous administrations are preferred because of their simplicity and low invasiveness. However, our experiments displayed their ineffectiveness in treating PKU. Intravenous administration resulted in insufficient $\mathrm{PAH}$ production to induce therapeutic effect, because only a small fraction of infused rAAV-hPAH enters the liver, the substantial target for PAH production. Much higher titers of rAAV vector should be infused to achieve effectiveness from intravenous administration. The ineffectiveness of intramuscular administration was likely due to the lack of synthesis or recycling of $\mathrm{BH}_{4}$, which helps $\mathrm{PAH}$ hydroxylate phenylalanine in tissues. $\mathrm{BH}_{4}$ is probably present in all tissues, but is generally abundant in liver (30). Recombinant viral vector sequestered in muscle would not induce phenylalanine oxidation at high activity, owing to a deficit of cofactor in this tissue. Expression of $\mathrm{BH}_{4}$ to an extent sufficient to assist enzymatic hydroxylation is required to overcome this kind of limitation of heterologous gene therapy.

Taken together, we revealed that recombinant AAVmediated human PAH gene transfer in mice induced a longterm, stable therapeutic effect without immunity and toxicity, resulting in satisfactory biochemical and phenotypic corrections in the PKU animal model. These positive results demonstrate that recombinant AAV vector-mediated gene therapy could provide useful and improved treatment options in the clinical control of PKU and other inherited metabolic disorders. Exploration of less invasive and more effective administration routes other than the hepatic portal vein and overcoming the ineffectiveness displayed in the female PKU mouse model are necessary to allow this strategy to be used for patients with PKU. 


\section{REFERENCES}

1. Lidsky AS, Law ML, Morse HG, Kao FT, Rabin M, Ruddle FH, Woo SL 1985 Regional mapping of the phenylalanine hydroxylase gene and the phenylketonuria locus in the human genome. Proc Natl Acad Sci U S A 82:6221-6225

2. Hoang L, Byck S, Prevost L, Scriver CR 1996 PAH Mutation Analysis Consortium Database: a database for disease-producing and other allelic variation at the human PAH locus. Nucleic Acids Res 24:127-131

3. Crawfurd MD, Gibbs DA, Sheppard DM 1981 Studies on human phenylalanine mono-oxygenase. I. Restricted expression. J Inherit Metab Dis 4:191-195

4. Erlandsen H, Stevens RC 1999 The structural basis of phenylketonuria. Mol Genet Metab 68:103-125

5. Menkes JH 1967 The pathogenesis of mental retardation in phenylketonuria and other inborn errors of amino acid metabolism. Pediatrics 39:297-308

6. Pietz J 1998 Neurological aspects of adult phenylketonuria. Curr Opin Neurol 11:679-688

7. Finkelson L, Bailey I, Waisbren SE 2001 PKU adults and their return to diet: predicting diet continuation and maintenance. J Inherit Metab Dis 24:515-516

8. Walter JH, White FJ, Hall SK, MacDonald A, Rylance G, Boneh A, Francis DE, Shortland GJ, Schmidt M, Vail A 2002 How practical are recommendations for dietary control in phenylketonuria? Lancet 360:55-57

9. Koch R, Azen CG, Friedman EG, Williamson ML 1982 Preliminary report on the effects of diet discontinuation in PKU. J Pediatr 100:870-875

10. Koch R, Hanley W, Levy H, Matalon R, Rouse B, Trefz F, Guttler F, Azen C, Friedman E, Platt L, de la Cruz F 2000 Maternal phenylketonuria: an international study. Mol Genet Metab 71:233-239

11. Cristiano RJ, Smith LC, Woo SL 1993 Hepatic gene therapy: adenovirus enhancement of receptor-mediated gene delivery and expression in primary hepatocytes. Proc Natl Acad Sci U S A 90:2122-2126

12. Fang B, Eisensmith RC, Li XH, Finegold MJ, Shedlovsky A, Dove W, Woo SL 1994 Gene therapy for phenylketonuria: phenotypic correction in a genetically deficient mouse model by adenovirus-mediated hepatic gene transfer. Gene Ther 1:247-254

13. Lin CM, Tan Y, Lee YM, Chang CC, Hsiao KJ 1997 Expression of human phenylalanine hydroxylase activity in $\mathrm{T}$ lymphocytes of classical phenylketonuria children by retroviral-mediated gene transfer. J Inherit Metab Dis 20:742-754

14. Nagasaki Y, Matsubara Y, Takano H, Fujii K, Senoo M, Akanuma J, Takahashi K, Kure S, Hara M, Kanegae Y, Saito I, Narisawa K 1999 Reversal of hypopigmentation in phenylketonuria mice by adenovirus-mediated gene transfer. Pediatr Res 45:465473

15. Halbert CL, Rutledge EA, Allen JM, Russell DW, Miller AD 2000 Repeat transduction in the mouse lung by using adeno-associated virus vectors with different serotypes. J Virol 74:1524-1532

16. Snyder RO, Miao CH, Patijn GA, Spratt SK, Danos O, Nagy D, Gown AM, Winther B, Meuse L, Cohen LK, Thompson AR, Kay MA 1997 Persistent and therapeutic concentrations of human factor IX in mice after hepatic gene transfer of recombinant AAV vectors. Nat Genet 16:270-276

17. Herzog RW, Yang EY, Couto LB, Hagstrom JN, Elwell D, Fields PA, Burton M, Bellinger DA, Read MS, Brinkhous KM, Podsakoff GM, Nichols TC, Kurtzman GJ, High KA 1999 Long-term correction of canine hemophilia B by gene transfer of blood coagulation factor IX mediated by adeno-associated viral vector. Nat Med 5:56-63

18. Snyder RO, Miao C, Meuse L, Tubb J, Donahue BA, Lin HF, Stafford DW, Patel S, Thompson AR, Nichols T, Read MS, Bellinger DA, Brinkhous KM, Kay MA 1999 Correction of hemophilia B in canine and murine models using recombinant adenoassociated viral vectors. Nat Med 5:64-70

19. Jung SC, Han IP, Limaye A, Xu R, Gelderman MP, Zerfas P, Tirumalai K, Murray GJ, During MJ, Brady RO, Qasba P 2001 Adeno-associated viral vector-mediated gene transfer results in long-term enzymatic and functional correction in multiple organs of Fabry mice. Proc Natl Acad Sci U S A 98:2676-2681

20. During MJ, Symes CW, Lawlor PA, Lin J, Dunning J, Fitzsimons HL, Poulsen D, Leone P, Xu R, Dicker BL, Lipski J, Young D 2000 An oral vaccine against NMDAR1 with efficacy in experimental stroke and epilepsy. Science 287:1453-1460

21. McDonald JD, Charlton CK 1997 Characterization of mutations at the mouse phenylalanine hydroxylase locus. Genomics 39:402-405

22. McDonald JD, Andriolo M, Cali F, Mirisola M, Puglisi-Allegra S, Romano V, Sarkissian CN, Smith CB 2002 The phenylketonuria mouse model: a meeting review. Mol Genet Metab 76:256-261

23. Bel Y, Jacobson KB, Ferre J 1992 A comparative study of Drosophila phenylalanine hydroxylase with a natural and a synthetic tetrahydropterin as cofactor. Comp Biochem Physiol B 103:557-562

24. Bennett J 2003 Immune response following intraocular delivery of recombinant viral vectors. Gene Ther 10:977-982

25. Thompson AJ, Tillotson S, Smith I, Kendall B, Moore SG, Brenton DP 1993 Brain MRI changes in phenylketonuria. Associations with dietary status. Brain 116:811821

26. Nakai H, Yant SR, Storm TA, Fuess S, Meuse L, Kay MA 2001 Extrachromosomal recombinant adeno-associated virus vector genomes are primarily responsible for stable liver transduction in vivo. J Virol 75:6969-6976

27. Duan D, Sharma P, Dudus L, Zhang Y, Sanlioglu S, Yan Z, Yue Y, Ye Y, Lester R, Yang J, Fisher KJ, Engelhardt JF 1999 Formation of adeno-associated virus circular genomes is differentially regulated by adenovirus E4 ORF6 and E2a gene expression. J Virol 73:161-169

28. Laipis PJ, Charron C, Ross K, Reyes L, Alexander JJ, Song S, Steele HA, Berns KI, Zori R, Flotte TR 2002 Long-term correction of phenylketonuria in an animal model by recombinant AAV-based gene therapy. J Inherit Metab Dis 25:615-616

29. Christensen R, Kolvraa S, Blaese RM, Jensen TG 2000 Development of a skin-based metabolic sink for phenylalanine by overexpression of phenylalanine hydroxylase and GTP cyclohydrolase in primary human keratinocytes. Gene Ther 7:1971-1978

30. Thony B, Auerbach G, Blau N 2000 Tetrahydrobiopterin biosynthesis, regeneration and functions. Biochem J 347:1-16 